\title{
H-Darrieus Wind Turbine with Blade Pitch Control
}

\author{
I. Paraschivoiu, ${ }^{1}$ O. Trifu, ${ }^{1}$ and F. Saeed ${ }^{2}$ \\ ${ }^{1}$ Département de Génie Mécanique, École Polytechnique de Montreal, CP 6079 succursale Centre-Ville, \\ Montreal, QC, Canada H3C $3 A 7$ \\ ${ }^{2}$ Aerospace Engineering Department, King Fahd University of Petroleum \& Minerals, Mail Box 1637, \\ Dhahran 31261, Saudi Arabia
}

Correspondence should be addressed to I. Paraschivoiu, ion.paraschivoiu@polymtl.ca

Received 1 September 2008; Revised 10 February 2009; Accepted 6 April 2009

Recommended by Shigenao Maruyama

\begin{abstract}
A procedure for computing the optimal variation of the blades' pitch angle of an $\mathrm{H}$-Darrieus wind turbine that maximizes its torque at given operational conditions is proposed and presented along with the results obtained on a $7 \mathrm{~kW}$ prototype. The CARDAAV code, based on the "Double-Multiple Streamtube" model developed by the first author, is used to determine the performances of the straight-bladed vertical axis wind turbine. This was coupled with a genetic algorithm optimizer. The azimuthal variation of the blades' pitch angle is modeled with an analytical function whose coefficients are used as variables in the optimization process. Two types of variations were considered for the pitch angle: a simple sinusoidal one and one which is more general, relating closely the blades' pitch to the local flow conditions along their circular path. A gain of almost $30 \%$ in the annual energy production was obtained with the polynomial optimal pitch control.
\end{abstract}

Copyright (C) 2009 I. Paraschivoiu et al. This is an open access article distributed under the Creative Commons Attribution License, which permits unrestricted use, distribution, and reproduction in any medium, provided the original work is properly cited.

\section{Introduction}

Following the 1973 energy crisis, large-scale research and development programs were initiated, directed toward finding replacement solutions to the limited fossil fuel reserves. Wind energy was given, along with photovoltaic, solar, hydroelectric, biomass, and other resources, particular attention as a renewable and environmentally friendly energy alternative. Its technological progress has been spectacular, especially in the last ten years and, due to its steady growth in competitiveness, wind power developed into a mainstream energy source in many countries worldwide. At the global scale, over $74000 \mathrm{MW}$ of wind power are already installed, and current estimates indicate that by 2030 wind energy could cover as much as $29 \%$ of world's electricity needs.

In the wind power domain two main technologies were considered as having the necessary potential for a viable development: the Horizontal Axis Wind Turbine (HAWT) and the Darrieus-type (lift-based) Vertical Axis Wind Turbine (VAWT). A number of features have made HAWT to be preferred and become the dominant design type, especially in the utility-scale (large and very large turbines) segment. But, in certain conditions (sites with highly turbulent wind like in the mountains or in urban environment), VAWTs seem to offer a better solution for the wind energy harnessing. If, through further and welltargeted research, increased attention is paid to the known VAWT drawbacks (a somewhat less overall efficiency than the one of an HAWT, difficult/impossible self-starting, lower output due to operation closer to the ground, higher level of vibration caused by the inherent torque ripple and dynamic stall of the blades), at least in the "small wind" domain the VAWT design might become a major player.

Among the most important problems that are now under study in the VAWT technology, the "variable pitch" for the $\mathrm{H}$-Darrieus turbines is regarded as a promising solution for the alleviation of the negative effects of the blades dynamic stall (efficiency loss, vibration), improvement of the rotor's self starting qualities, and torque ripple smoothing [1-3].

At École Polytechnique de Montreal, Canada, in the wind energy research the major effort is devoted toward the development and improvement of the performance prediction of VAWTs [4]. The variable pitch is also included in the current research subjects in this domain, and results were already published [8], obtained from the analysis that was carried out to determine if the performance of a 


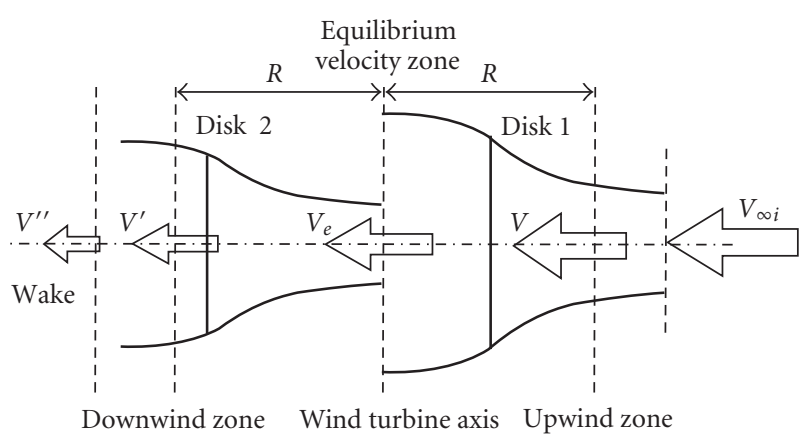

Figure 1: The two actuator disks model.

VAWT, in terms of the power output, could be improved by simulating the operation of the blade just below stall. The present study aimed at determining if a more general cyclical pitch variation can be determined, so as to maximize the performance of an H-Darrieus (straight bladed) vertical axis wind turbine at given operation conditions. In order to perform this investigation, an optimization package was set up to serve in the determination of the optimal variation of the blade's pitch angle for a small two-bladed VAWT. The paper presents first the main components of the numerical tool that was developed. Then, the results of an optimization case are discussed. Finally, several conclusions are formulated at the end of the paper.

\section{The Optmization Tool}

Since the local flow parameters on the blades vary along their circular path and differ quite significantly between the upwind and the downwind parts of the rotor, an optimization procedure had to be employed to determine the best law of variation of the blades' pitch angle. In the present study a tool for numerical optimization was set up by coupling the code CARDAAV, which computes the flow through and the performances of a VAWT, to an optimizer based on the genetic algorithm method. These (main) components of the optimization package are briefly presented in the following sections, along with the objective function, its variables, and the constraints that were imposed on their value during the optimization process.

2.1. The CARDAAV Code. CARDAAV, the numerical tool used in this analysis, is based on an improved version of the "double-multiple streamtube" (DMS) model [4]. This model considers a partition of the rotor in streamtubes and treats each of the two blade elements defined by a given streamtube as an actuator disk. Figure 1 illustrates such a streamtube and shows the values of the velocity of the flow at a number of key stations along it. Disk 1 represents the upwind blade element while disk 2 represents the downwind blade element.

The actuator disk theory is based on the momentum conservation; therefore, the velocities of the wind must be known in order to compute the force acting on the disks. The different values of the velocity (see notations in Figure 1 and relations (1)) depend on the incoming ("undisturbed") wind velocity and on the interference factors $\mathbf{u}$ and $\mathbf{u}$ ' :

$$
\begin{aligned}
V & =u V_{\infty i}, \\
V_{e} & =(2 u-1) V_{\infty i}, \\
V^{\prime} & =u^{\prime}(2 u-1) V_{\infty i} .
\end{aligned}
$$

To determine the interference factors, a second set of equations is used. Those equations are derived from the blade element theory [4], which equates, in each streamtube, the normal forces acting on the upwind and downwind blade elements to the forces acting upon the actuator disks. To compute the normal and tangential forces, the blade element theory is applied, and the lift $\left(C_{l}\right)$ and $\operatorname{drag}\left(C_{d}\right)$ coefficients, obtained from the airfoil data, are used.

For the upwind interference factor $u$, the following expression, relating it to the azimuthal angle $\theta$, is obtained:

$$
u(\theta)=\frac{K K_{0} \eta}{\left[K K_{0} \eta+\int_{\theta-\Delta \theta / 2}^{\theta+\Delta \theta / 2}(W / V)^{2}\left(C_{N} \cos \theta+C_{T}(\sin \theta / \cos \delta)\right) d \theta\right]}
$$

with

$$
K=\frac{8 \pi r}{N c}, \quad K_{0}=\sin \left(\theta+\frac{\Delta \theta}{2}\right)-\sin \left(\theta-\frac{\Delta \theta}{2}\right) .
$$

A similar set of equations is derived for the downwind interference factor $u^{\prime}$. An interference factor equal to 1 is assumed at the beginning of the iterative process. Once the force given by the blade element theory equates the one given by the actuator disk theory, the convergence is achieved and the upwind and downwind velocities are obtained. Then the torque and the mechanical power are computed.

CARDAAV has the capability to analyze several predefined or user-defined rotor shapes with straight or curved blades (parabola, catenary, ideal and modified troposkien, and Sandia shape). The code requires three main sets of input data, giving the geometry definition of the wind turbine (diameter, height, blade section airfoil, blade shape, etc.), the operational conditions (wind velocity, rotational speed, atmospheric conditions) and the main control parameters (convergence criterion, computation of the secondary effects, and the effect of dynamic stall). The software includes several dynamic stall semiempirical models: Gormont [5] and its variations (Strickland, Paraschivoiu, and Berg) and the one based on the indicial method [4]. Dynamic stall results in increased peak aerodynamic torque and affects the structural fatigue of the Darrieus turbine. This effect significantly impacts the drive-train generator sizing and system reliability. The dynamic stall used in this study was the Berg version of the Gormont model, because it was found out to be the best correlated with the experimental studies carried out on similar rotor configurations as those used in the present investigation. CARDAAV is also able to account for the so-called "secondary effects," such as those due to the rotating central tower, struts, and spoilers.

CARDAAV has made it possible to design, analyze, and build more efficiently and at lower costs wind energy systems 


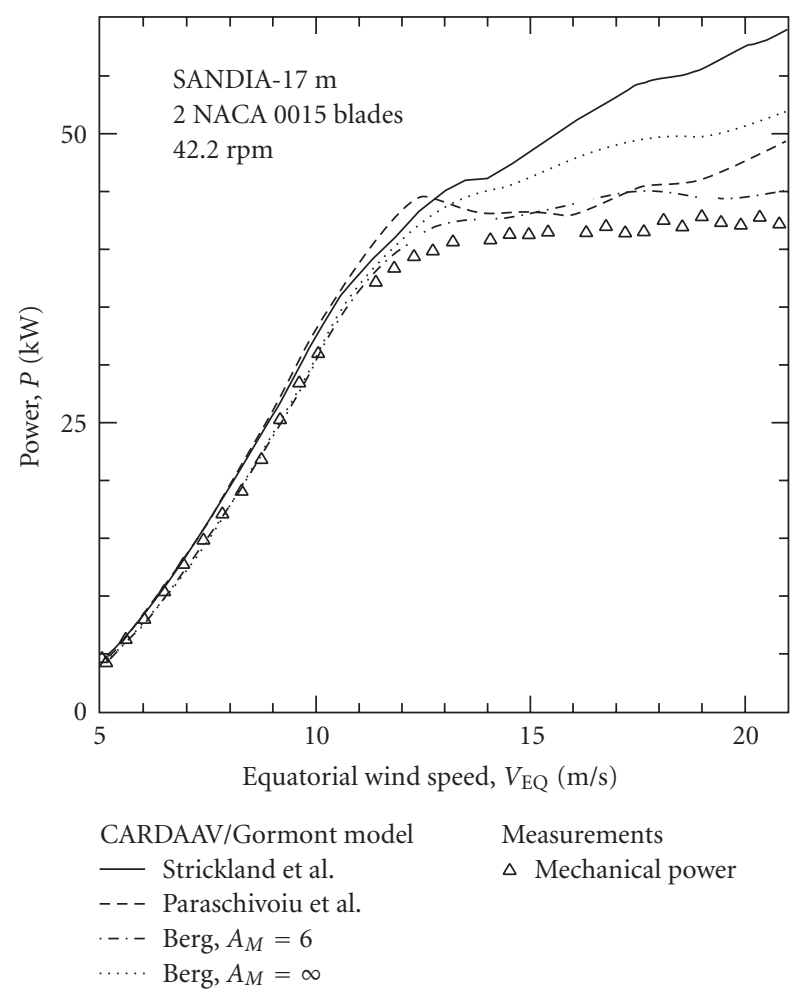

FIGURE 2: Comparison of CARDAAV results with experimental and other numerical predictions. (adapted from Paraschivoiu 2002) [4].

such as the Darrieus-type VAWT. The code is used to determine, at specified operational conditions, aero-dynamic forces and power output of VAWTs of any blade geometry. Wind speed can vary with height above ground according to a power law. The program output consists of the localinduced velocities, the local Reynolds numbers and angle of attack, the blade loads, and the azimuthal torque and power coefficient data. Each of these is calculated separately for the upwind and downwind halves of the rotor. The numerical models used by the program have been validated for different Darrieus-type VAWTs, through comparison with experimental data obtained from laboratory tests (wind or water tunnels) or from field tests, thus making CARDAAV a very attractive and efficient design and analysis tool.

In Figure 2 the power output of the SANDIA $17 \mathrm{~m}$ wind turbine computed with CARDAAV is compared with experiments and results provided by other numerical codes. $A M$ is an empirical constant used to correct $C_{l}$ and $C_{d}$ for dynamic stall effects [6].

2.2. The Optimizer. To search for the best pitch variation law, an optimization strategy was adopted, namely, one that uses a genetic algorithm (GA) method. At the beginning of the optimization process, a genetic algorithm randomly selects an initial "population" composed of "individuals", which are solutions of the analyzed problem computed for particular, randomly selected, values of the optimization variables. Three operations are typically performed by the genetic algorithms on the analyzed "population": "selection" (choice of the "individuals" for the next generation, according to a "survival of the fittest" criterion), "crossover" (operation which allows information exchange between the "individuals" by swapping parts of the parameter vector in an attempt to get better "individuals") and "mutation" (operation which introduces new or prematurely lost information in the form of random changes applied to randomly chosen vector components).

Like in any optimization study, an "objective function" had to be defined. In this case the inverse of the rotor power, for given conditions of operation (wind speed, rotational speed)

$$
F=\frac{1}{P}
$$

was used as optimization function $F$.

On the other hand, for the pitch angle the following analytical expression was considered:

$$
\tau=x_{1} \cos \theta+x_{2}(\sin \theta)^{x_{3}} .
$$

For different values given to the optimization variables $x_{1}, x_{2}$, and $x_{3}$, the variation of the blade pitch angle $\tau$ with the angle of azimuth $\theta$ will be different. Since the local angle of attack $\alpha$ of a blade element

$$
\alpha=\sin ^{-1}\left[\frac{\cos \theta \cos \tau-(X-\sin \theta) \sin \tau}{\sqrt{(X-\sin \theta)^{2}+\cos ^{2} \theta}}\right]
$$

contains the pitch angle, the later influences the aerodynamic characteristics, the torque, and ultimately the power output of the rotor. Hence, through relations (5) and (6) an indirect link is established between the objective function (4) and the optimization variables $x_{1}, x_{2}$, and $x_{3}$, which control the variation of $\tau$.

The genetic algorithm evolution strategy optimization package, GENIAL v1.1 [7], was employed to minimize the objective function. This code includes three main modules, which perform the above mentioned operations. A number of parameters are available in each module to control its functioning during the optimum search process.

As mentioned above, the coefficients $x_{1}, x_{2}$, and $x_{3}$ of the pitch variation function (5) were used as optimization variables. Their values were subjected to certain constraints, to avoid any possible mathematical invalidity and to keep the pitch angle within reasonable or practical (technically feasible) limits.

2.3. The Optimization Package. To set up the optimization package, including GENIAL and CARDAAV as principal components, a main program (MAIN) and a new subroutine (PITCH) had to be coded.

When the program is launched, MAIN reads some of the parameters that control the optimization process, namely, those that are frequently changed (size of the "population"number of "individuals", number of evaluations, constraints to be set on the optimization variables). These parameters have to be provided through the keyboard when a new 


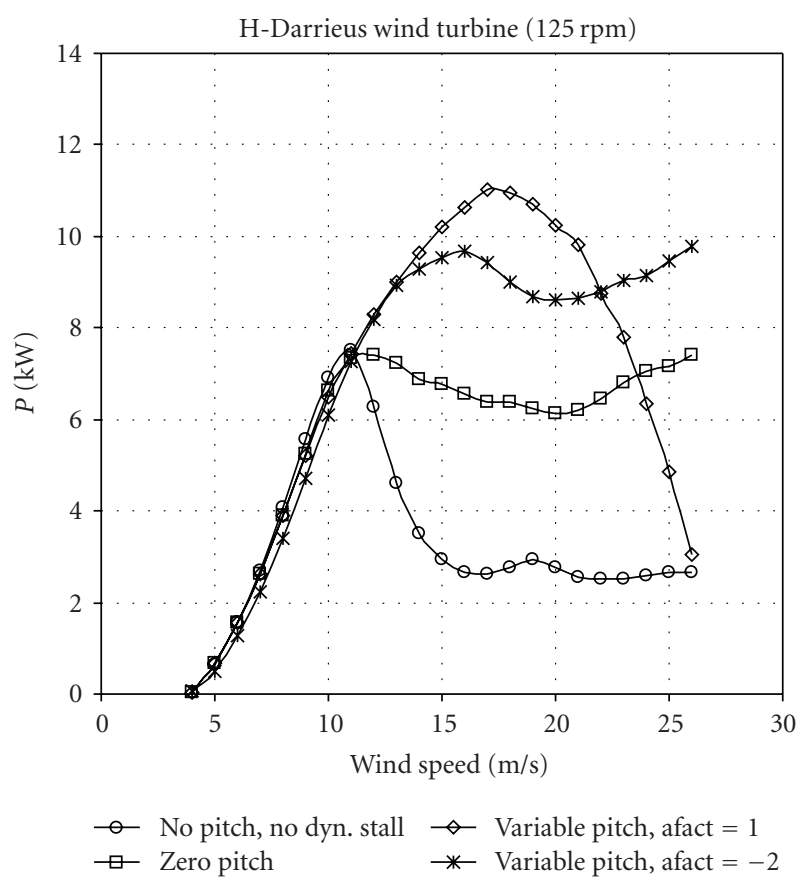

Figure 3: Power versus wind speed for the $7 \mathrm{~kW}$ VAWT with fixed and variable pitch blades.

optimization is initiated. Then, MAIN calls the optimizer (GENIAL), which takes control and carries through the optimization process. For each combination of the optimization variables, defining a distinct 'individual", GENIAL calls (using a "system function") PITCH then CARDAAV, which performs the analysis of the VAWT for that specific variation of the blades' pitch angle. With the turbine power, calculated by CARDAAV, the objective function (4) is determined and, based on it, the "fitness function" which characterizes that "individual" is obtained. Depending on its "fitness", an "individual" can be maintained or eliminated from the "population" during the optimization process. Selection, crossover, and mutation are used to advance the "population" from one optimization cycle to the next until the optimum or the predefined limit of evolutions is reached. At the end of the optimization, MAIN outputs the optimal values of the $x_{1}, x_{2}$, and $x_{3}$ variables (as found through optimization), which define the best variation law for the pitch angle. Corresponding to this, the performance characteristics of the turbine are computed and stored in a file for postprocessing purposes.

As the name indicates, the subroutine PITCH uses relation (5) to calculate the pitch angle over the entire circular trajectory of the blades, based on the values of $x_{1}, x_{2}$, and $x_{3}$ received from GENIAL. It stores the azimuthal and the pitch angles in a file where CARDAAV seeks this information before performing each new analysis.

\section{Results}

This study was carried out on an H-Darrieus VAWT, having two constant-chord blades with an NACA 0015 airfoil cross

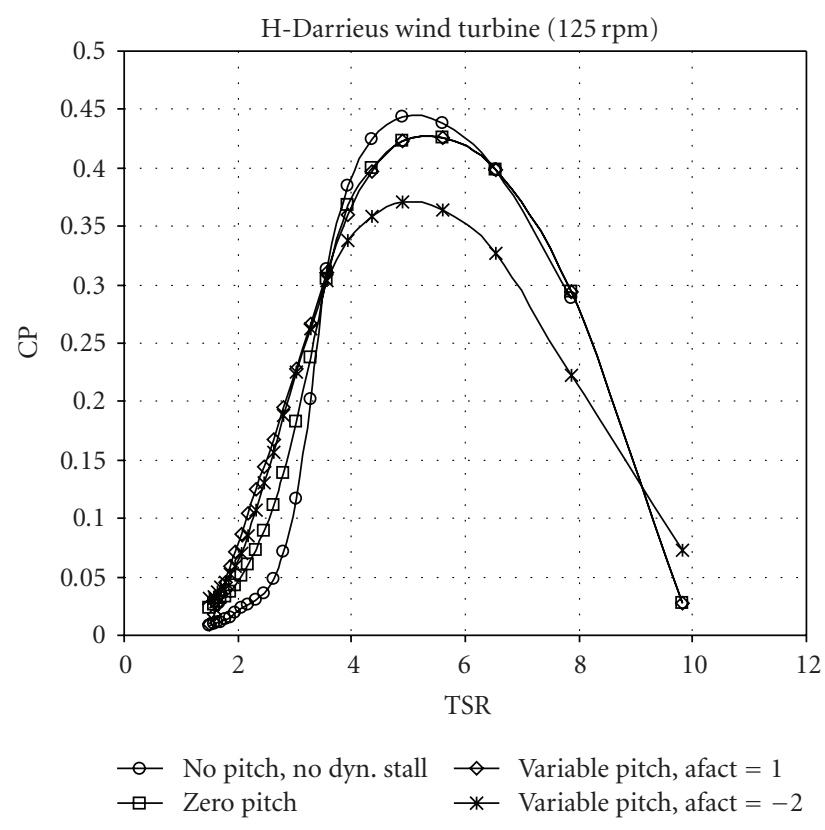

FIgure 4: Power coefficient versus TSR for the $7 \mathrm{~kW}$ VAWT with fixed and variable pitch blades.

TABLE 1: Characteristics of the rotor used in the study.

\begin{tabular}{lc}
\hline Parameter & Value \\
\hline Rotor diameter & $6.0 \mathrm{~m}$ \\
Rotor height & $6.0 \mathrm{~m}$ \\
Blade length & $6.0 \mathrm{~m}$ \\
Blade chord (constant) & $0.2 \mathrm{~m}$ \\
Blade airfoil & NACA 0015 \\
Number of blades & 2 \\
Rotor ground clearance & $3 \mathrm{~m}$ \\
\hline
\end{tabular}

section. It is a small, $7 \mathrm{~kW}$ rated power prototype, its rotor having the (main) geometrical characteristics given in Table 1.

The performance (power, power coefficient, Figures 3 and 4) of this turbine was computed with CARDAAV in several situations: without taking into account the influence of the dynamic stall, by applying the dynamic stall correction, with a blade pitch that had a sinusoidal variation and with a blade pitch that varied according to relation (5) in which: $x_{1}=2, x_{2}=4, x_{3}=3$. These calculations, as well as all the other that are presented in this paper, have been performed for a constant rotational speed of $125 \mathrm{rpm}$ and at one or several different wind speed values.

As can be observed on the graph of Figure 3, for the "zero pitch" prototype CARDAAV predicted a rated power of around $7 \mathrm{~kW}$ (at $12 \mathrm{~m} / \mathrm{s}$ wind speed). The importance of taking into consideration the effects of the dynamic stall is also clearly visible in the higher winds range $(>10 \mathrm{~m} / \mathrm{s})$ where the blades angle of attack exceeds the static-stall incidence. The prototype with a sinusoidal variation ( afact $=1$ case) of the blade pitch has a significantly increased power output 
TABle 2: Parameter settings used in GENIAL's modules.

\begin{tabular}{|c|c|}
\hline \multicolumn{2}{|c|}{ Evolution Module } \\
\hline Function & User function \\
\hline Worst fitness & $10 \mathrm{E} 20$ \\
\hline Problem type & Minimization \\
\hline Number of variables & 3 \\
\hline Number of evolutions & 1500 \\
\hline \multicolumn{2}{|c|}{$\begin{array}{l}\text { Population Module } \\
\end{array}$} \\
\hline Population size & 100 \\
\hline Reproduction model & $\begin{array}{c}\text { Steady state } \\
\text { without } \\
\text { duplicates } 10\end{array}$ \\
\hline Parent selection method & $\begin{array}{c}\text { Stochastic } \\
\text { tournament } \\
0.6\end{array}$ \\
\hline Replacement method & $\begin{array}{c}\text { Exponential } \\
\text { ranking } 0.3\end{array}$ \\
\hline \multicolumn{2}{|c|}{ Reproduction Module } \\
\hline Number of operators & 2 \\
\hline Uniform arithmetical crossover & 35.01 .00 .5 \\
\hline Uniform creep & 5.01 .00 .001 \\
\hline
\end{tabular}

in this domain, but only up to a wind speed of about $17 \mathrm{~m} / \mathrm{s}$ where it generates $70 \%$ more power than the zero pitch prototype. Beyond that speed its performance decreases rapidly, and this pitch variation becomes counter-productive (although it might be useful for reasons of turbine protection in high winds). The maximum amplitude in the sinusoidal pitch law is set equal to the maximum difference between the local geometric angle of attack $\alpha$ and the blade static-stall angle $\alpha_{\text {stall }}[8]$.

A good performance in winds above $11 \mathrm{~m} / \mathrm{s}$ was also obtained with the variable pitch given by relation (5), in which $x_{1}=2, x_{2}=4$, and $x_{3}=3$ were employed (afact $=-2$ case). For $V_{\infty}>11 \mathrm{~m} / \mathrm{s}$, this produces roughly $35 \%$ more power than the "standard" (zero pitch) prototype but is less performing than the one with the sinusoidal pitch and, especially, has a lower power output and lower efficiency (Figure 4$)$ in the low winds $\left(V_{\infty}<11 \mathrm{~m} / \mathrm{s}\right)$ domain, hence at higher TSRs. However, relation (5) is only one possible, and not very general, way of modeling the pitch variation.

Moreover, the values that were used for the $x_{1}, x_{2}$, and $x_{3}$ constants are certainly not necessarily the best, which explains the poorer performance of the prototype that used this pitch variation law. Therefore, optimization was used to find the best possible values for $x_{1}, x_{2}$, and $x_{3}$ and enhances the turbine's performance through an optimized pitch variation.

At $125 \mathrm{rpm}$, the maximum of the power coefficient is attained for $\mathrm{TSR} \cong 5.3$, regardless of the blade pitch. But, since the maximum $\mathrm{CP}$ attained with the pitch given by relation (5) is below the value obtained with zero pitch or with the sinusoidal pitch (Figure 4), the optimization was performed at the operation conditions that correspond to

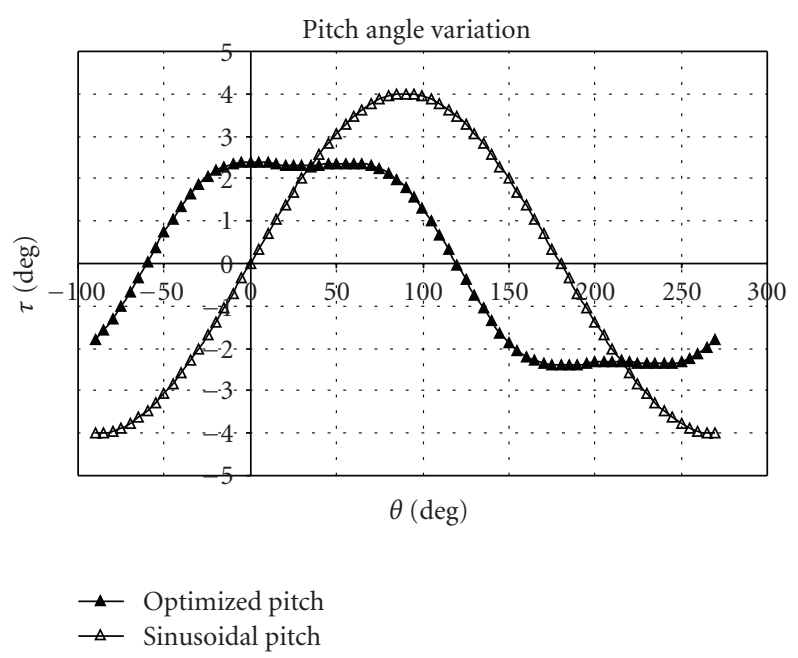

FIgURE 5: Optimal variation of the blade pitch angle.

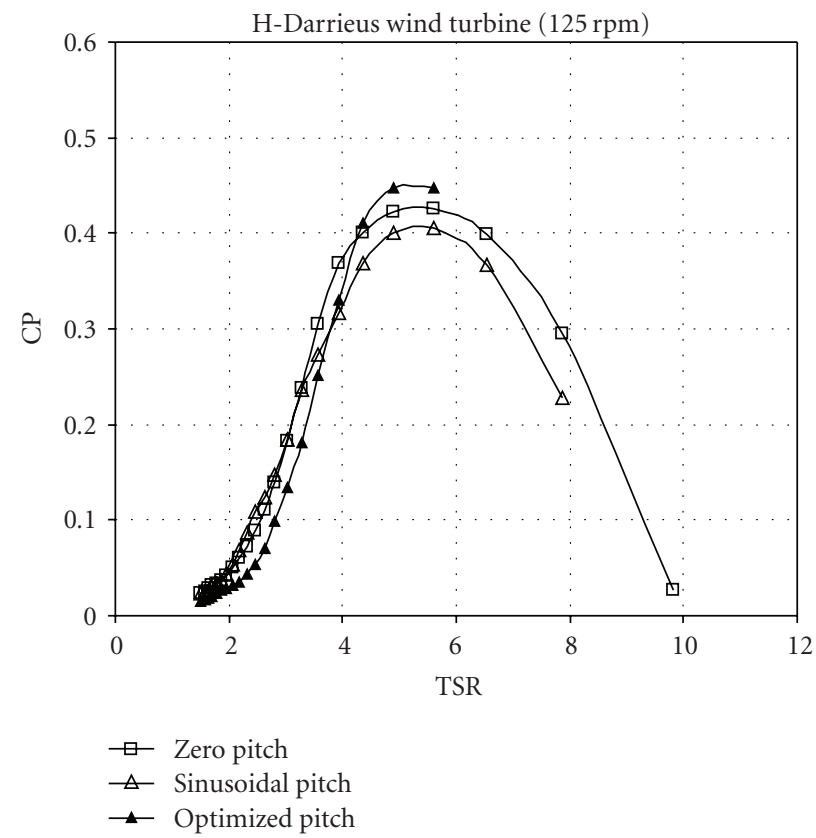

FIgURE 6: Power coefficient versus TSR for the $7 \mathrm{~kW}$ VAWT with fixed and optimized variable pitch.

TSR $=5.3\left(V_{\infty}=7.3 \mathrm{~m} / \mathrm{s}\right.$, at $125 \mathrm{rpm}$ for the analyzed rotor).

For all the optimizations that were carried out in the present study, the parameters which control the functioning of the three main modules of GENIAL were set to the values given in Table 2. At the beginning of a new optimization, GENIAL generated a "population" of 100 "individuals". In the case of this study an "individual" corresponded to a particular variation of the blades' pitch, as defined by the values given to the coefficients $x_{1}, x_{2}$, and $x_{3}$. A random number generator is used by GENIAL to produce the first "population". A total of 1500 cycles was found to be sufficient, in the context of the given optimization 


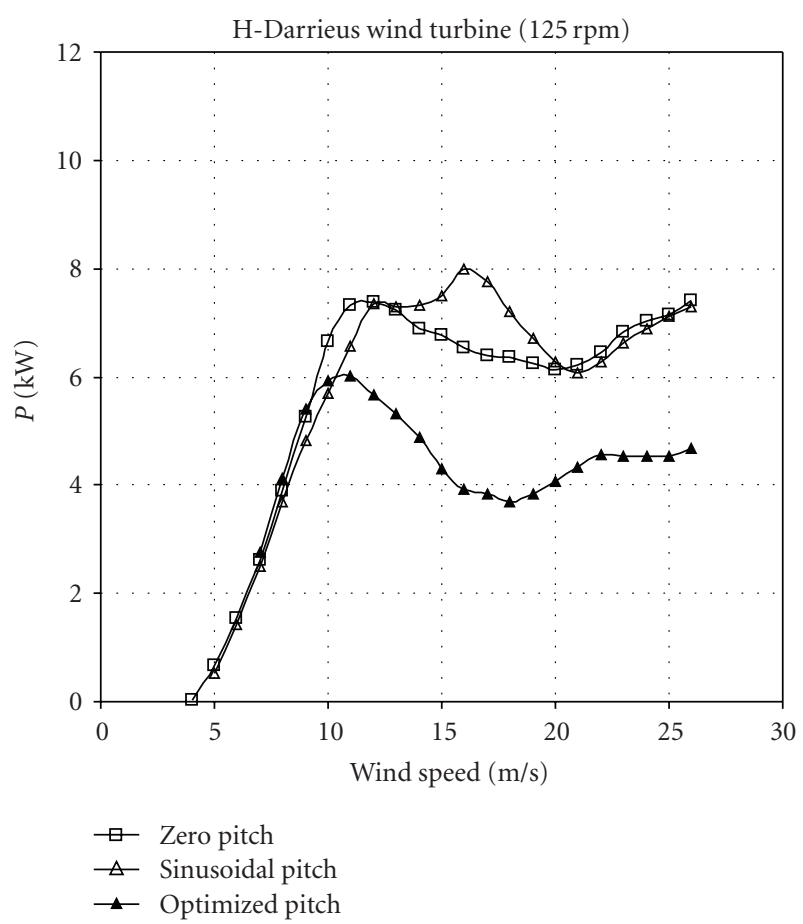

FIGURe 7: Power versus wind speed for the $7 \mathrm{~kW}$ VAWT with fixed and optimized variable pitch.

problem, to determine the optimum values of the coefficients $x_{1}, x_{2}$, and $x_{3}$ which ensured the minimum of the objective function.

At the end of the optimization, for the optimization variables $x_{1}, x_{2}$, and $x_{3}$ the following values were obtained: $x_{1}=2.403, x_{2}=1.798$, and $x_{3}=3.009$. When replaced in relation (5), these define the blade pitch angle variation illustrated in Figure 5. For comparison, on the same graph is also shown a sinusoidal variation with the maximum amplitude (difference between the local geometric angle of attack $\alpha$ and the blade static-stall angle $\alpha_{\text {stall }}$ ) of 4 degrees. The optimal pitch variation has smaller amplitude $\left(\cong 2.2^{\circ}\right)$ and relatively extended intervals of quasiconstant value, which reduce the need to continuously vary the blade pitch, thus simplifying the variable pitch mechanism.

As one can notice by comparing the graphs in Figures 6 and 4, a clear improvement (over 21\% increase) in the wind turbine efficiency (CP) was obtained through the optimization carried out at the considered operation conditions $\left(V_{\infty}=7.3 \mathrm{~m} / \mathrm{s}\right.$, at $\left.125 \mathrm{rpm}\right)$.

However, the benefits of the optimized variation of the pitch do not extend far beyond a relatively narrow domain around this "point" of optimization. If the same pitch variation is used in off-design conditions, at other wind speeds (other TSRs), the turbine efficiency becomes lower than the one of the zero pitch version (Figure 6). In winds above $9 \mathrm{~m} / \mathrm{s}$ this is clearly visible on the power curve (Figure 7), which shows that the pitch variation, which is optimal at $V_{\infty}=7.3 \mathrm{~m} / \mathrm{s}$ (see the detail in Figure 8), greatly reduces the turbine power output if used in higher winds.

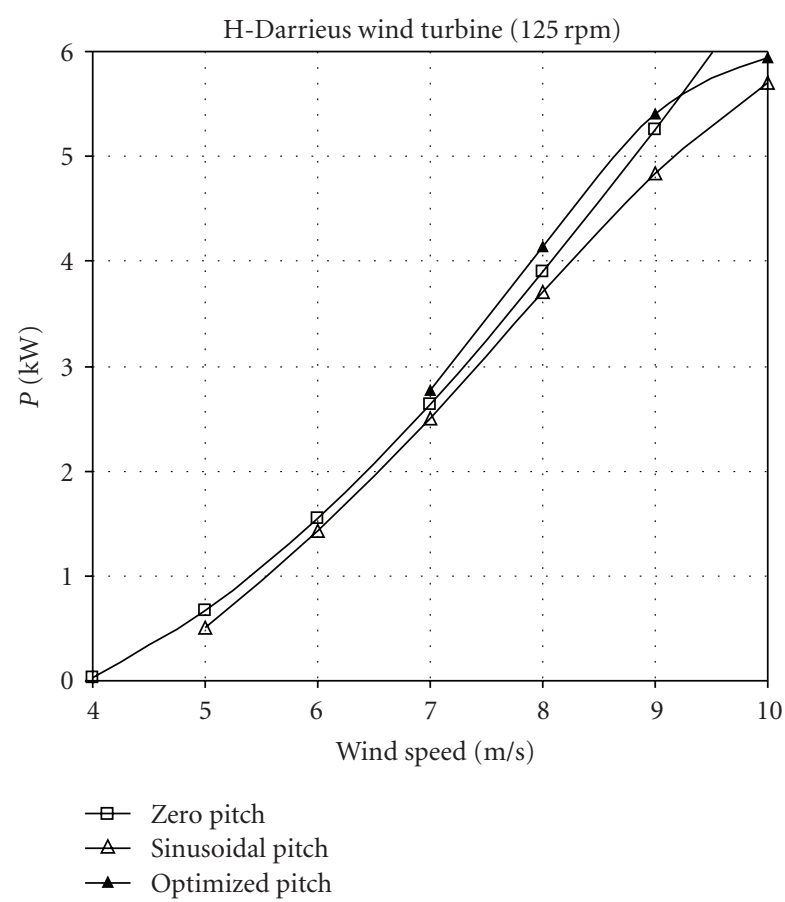

FIGURE 8: Power versus wind speed for the $7 \mathrm{~kW}$ VAWT with fixed and optimized variable pitch (detail).

Therefore, the optimization of the pitch variation was also carried out at other wind speeds up to the rated wind. Indeed, since high winds are relatively rare, a loss in the turbine efficiency beyond the rated wind speed is not very penalizing in terms of annual energy production. Instead, by enhancing the turbine efficiency and its power output in the low-speed range, an increase of almost 30\% in the annual energy production was obtained for the analyzed prototype. This is certainly an interesting gain, which might fully justify the supplementary costs related to the implementation of a variable pitch system. A Rayleigh distribution for the wind probability density and a $6 \mathrm{~m} / \mathrm{s}$ mean wind speed were considered to calculate the turbine's annual energy production.

\section{Conclusions}

1An optimization tool, combining the CARDAAV code with a genetic algorithm-based optimizer, was developed and used to optimally define the variation of the blade pitch angle of an $\mathrm{H}$-Darrieus (straight bladed) $7 \mathrm{~kW}$ wind turbine. The optimized pitch enhanced the turbine performance at the design point and in a relatively narrow wind speed domain around it. In "off-design" conditions the optimized pitch was detrimental to the turbine performance, thus imposing optimizations at other wind speeds below the rated wind. With a pitch variation optimized throughout the low wind domain, an increase of almost 30\% in the annual energy production of the turbine could be obtained. This could justify the supplementary expenses related to the implementation of the variable pitch system. 


\section{Nomenclature}

$\begin{array}{ll}C_{d}: & \text { Blade section drag coefficient } \\ C_{l}: & \text { Blade section lift coefficient } \\ C_{N}: & \text { Blade section normal force coefficient } \\ C P: & \text { Power coefficient } \\ C_{T}: & \text { Blade section tangential force coefficient } \\ c: & \text { Olade chord, m } \\ F: & \text { Numbective function } \\ N: & \text { Interference factor } \\ P: & \text { Local induced velocity, } \mathrm{m} / \mathrm{s} \\ u: & \text { Free stream wind velocity, } \mathrm{m} / \mathrm{s} \\ V: & \text { Local tip-speed ratio, } r \omega / V \\ V \infty: & \text { Local angle of attack, deg } \\ X: & \text { Angle between blade normal and } \\ \alpha: & \text { equatorial plane, deg } \\ \delta: & \text { Non-dimensional radius, } r / R \\ \eta: & \text { Azimuthal angle, deg } \\ \theta: & \text { Blade pitch angle, rad } \\ \tau: & \text { Optimization variables }\end{array}$

\section{References}

[1] I. S. Hwang, S. Y. Min, I. O. Jeong, Y. H. Lee, and S. J. Kim, "Efficiency improvement of a new vertical axis wind turbine by individual active control of blade motion," in Smart Structures and Materials 2006: Smart Structures and Integrated Systems, vol. 6173 of Proceedings of SPIE, pp. 316-323, San Diego, Calif, USA, March 2006.

[2] B. K. Kirke, Evaluation of self-starting vertical axis wind turbines for standalone applications, Ph.D. thesis, Griffith University, Gold Coast, Australia, April 1998.

[3] N. C. K. Pawsey, Development and evaluation of passive variablepitch vertical-axis wind turbines, Ph.D. thesis, The University of New South Wales, Sydney, Australia, November 2002.

[4] I. Paraschivoiu, Wind Turbine Design with Emphasis on the Darrieus Concept, Polytechnique International Press, École Polytechnique de Montréal, Montréal, Canada, 2002.

[5] R. E. Gormont, "A mathematical model of unsteady aerodynamics and radial flow for application to helicopter rotors," Tech. Rep. TR 72-67, US Army Air Mobility R\&D Laboratory, Vertol Division, Philadelphia, Pa, USA, May 1973.

[6] I. Paraschivoiu and F. Delclaux, "Double-multiple streamtube model with recent improvements," Journal of Energy, vol. 7, no. 3, pp. 250-255, 1983.

[7] H. Wildell, GENIAL. version 1.1, August 1997, http:// hjem.get2net.dk/widell/genial.htm.

[8] Y. Staelens, F. Saeed, and I. Paraschivoiu, "A straight-bladed varible-pitch VAWT concept for improved power generation," in Proceedings of the 22nd ASME Wind Energy Symposium held in Conjunction with the 41st Aerospace Sciences Meeting of Exhibit, Reno, Nev, USA, January 2003, AIAA paper 2003-0524. 

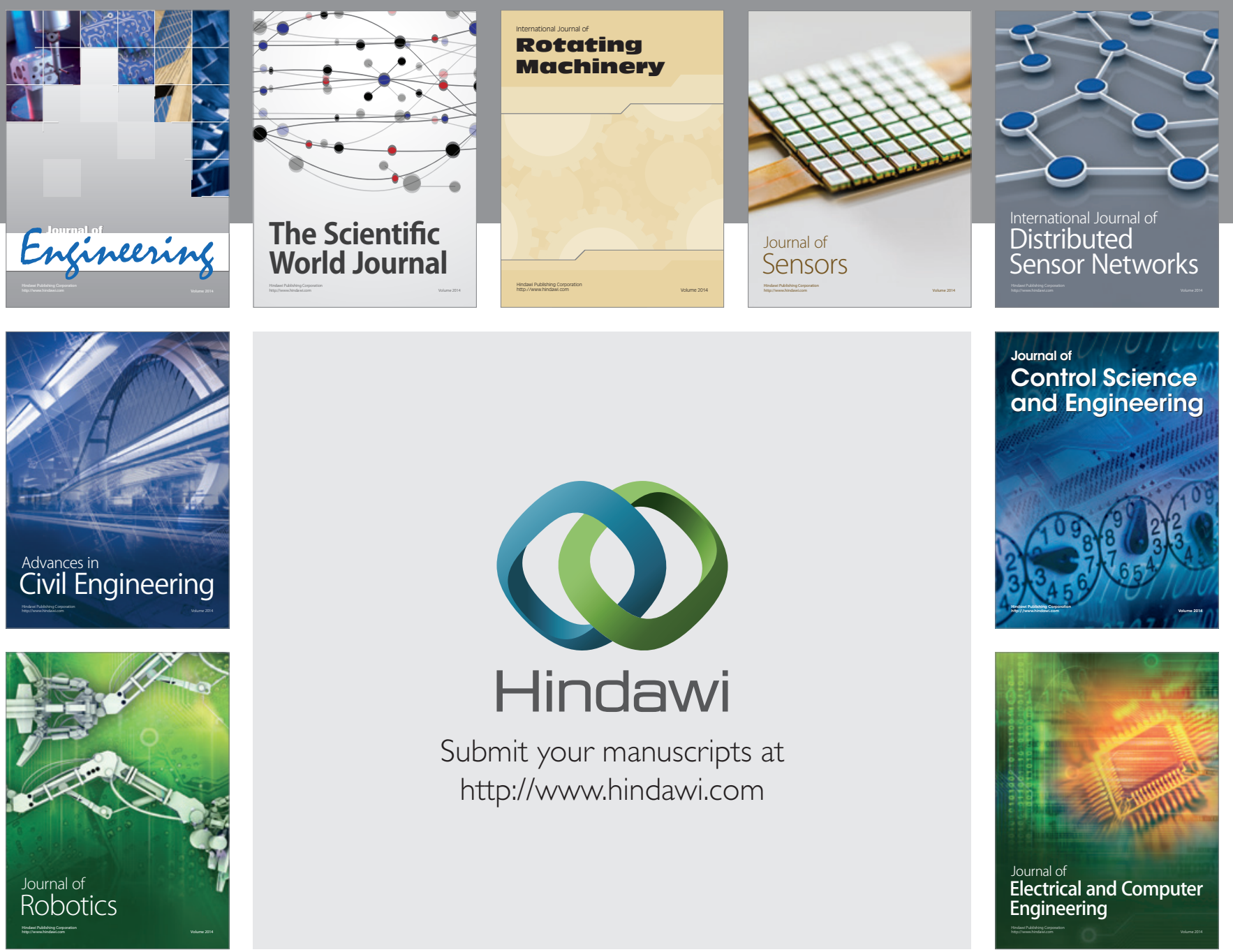

Submit your manuscripts at

http://www.hindawi.com
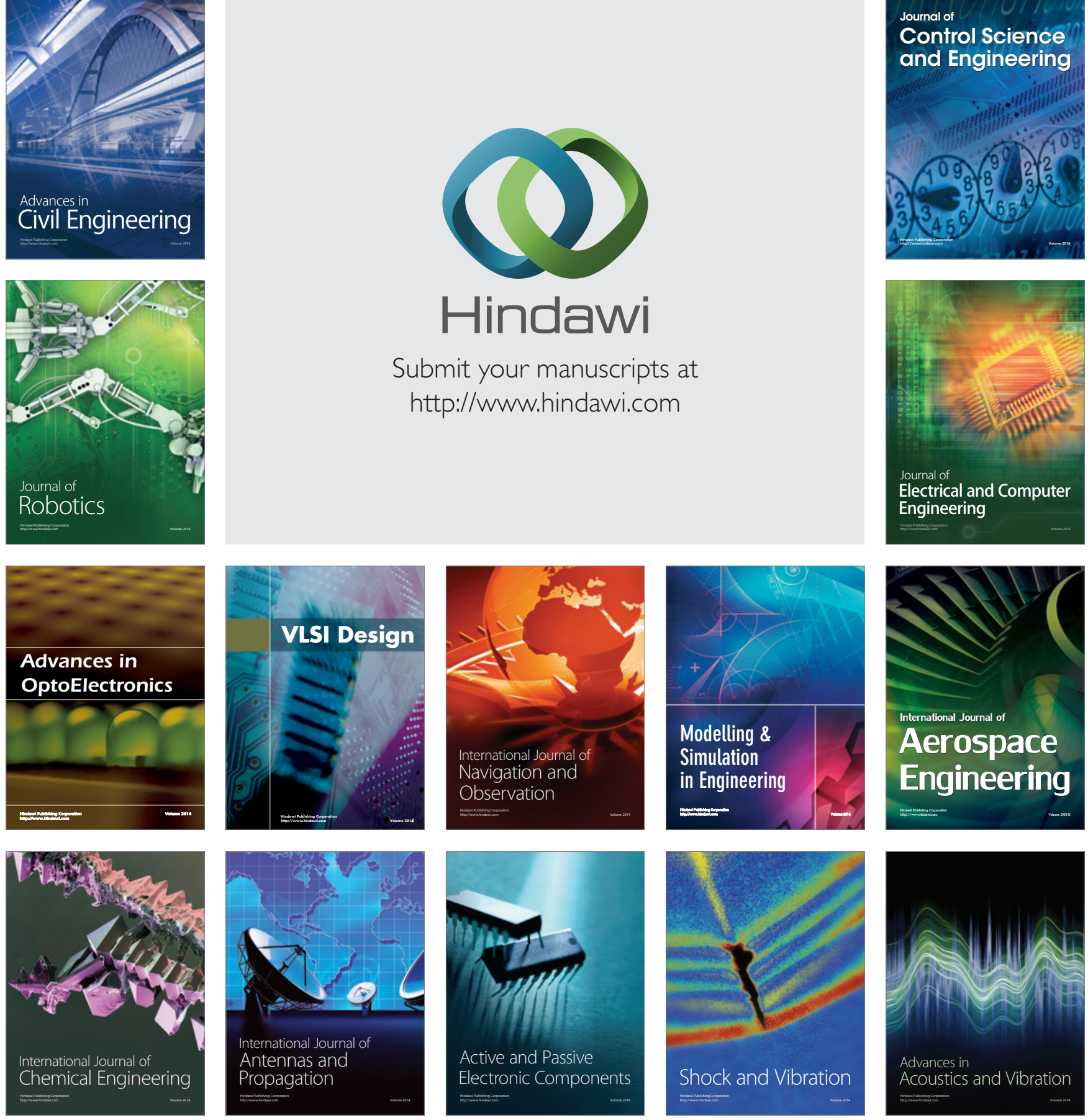